\title{
Student perceptions of iPads as mobile learning devices for fieldwork
}

Article

Accepted Version

Welsh, K. E., Mauchline, A., Powell, V., France, D., Park, J. R. and Whalley, W. B. (2015) Student perceptions of iPads as mobile learning devices for fieldwork. Journal of Geography in Higher Education, 39 (3). pp. 450-469. ISSN 1466-1845 doi: https://doi.org/10.1080/03098265.2015.1066315 Available at https://centaur.reading.ac.uk/42828/

It is advisable to refer to the publisher's version if you intend to cite from the work. See Guidance on citing.

To link to this article DOI: http://dx.doi.org/10.1080/03098265.2015.1066315

Publisher: Taylor \& Francis

All outputs in CentAUR are protected by Intellectual Property Rights law, including copyright law. Copyright and IPR is retained by the creators or other copyright holders. Terms and conditions for use of this material are defined in the End User Agreement.

\section{www.reading.ac.uk/centaur}

\section{CentAUR}

Central Archive at the University of Reading 
Reading's research outputs online 


\section{Introduction}

\subsection{Mobile learning and fieldwork}

Fieldwork is an integral component of a wide range of undergraduate and postgraduate degree programmes including geography (Kent, Gibertson \& Hunt., 1997), earth sciences, environmental sciences (Maskall \& Stokes, 2007), biosciences (Maw et al., 2012), archaeology and anthropology. Use of technology has become an increasingly prominent aspect of fieldwork teaching and learning and over time has grown in sophistication since the days of Gardiner and Unwin (1986) who took desktop computers on fieldtrips to motivate students by allowing them to process their results at the fieldwork accommodation. There are many examples of how technology has been used to support fieldwork and mobile learning (See France et al., forthcoming), including providing remote access to field sites for students with mobility impairments (reviewed by Welsh et al., 2013) Fletcher et al. (2007) identified that, rather than only having technology available pre and post fieldwork or during the evenings of residential fieldwork, having technology available "at the field base or even in the field" (p.328) offers "the greatest potential opportunities for enhanced pedagogic practice [...] to improve the immediacy of data analysis" (p.328).

With mobile technologies such as smartphones increasing in popularity since 2007 (Welsh \& France, 2012) and tablet computers increasing in popularity since 2010, there is huge potential to use these mobile technologies as data capture devices in the field to enhance the student learning experience. The five main benefits as of using mobile devices in education as identified by Melhuish and Falloon (2010) are: portability, affordable and ubiquitous access, situated "just-in-time" learn opportunities, connection and convergence and individualised and personalised experiences. Whilst mobile learning in the classroom has been researched extensively (e.g. Ruchter, Klar \& Geiger, 2010; Karsenti \& Fievez. 2013; Gikas \& Grant (2013); O’Bannon \& Thomas, 2014), little research has been conducted into mobile learning and its potential for enhancing the student learning and engagement during field courses.

Welsh et al. (2013) identified that practitioners introduced technology to field courses for a range of pedagogic reasons such as improving speed and ease of data collection and processing, to engage students and to ensure the immediacy of data analysis was not lost. This research concluded that the practitioner focus remains heavily on pedagogy which was not seemingly the case during an earlier piece of research by Fletcher et al. (2007) which found that 
practitioners were using technology for technology's sake and did not have a pedagogic rationale for introducing technology into field courses. This, however, may reflect that such technology is now ubiquitous and that it has given practitioners a chance to consider the specific benefits it provides to enhancing fieldwork and have crafted innovative, pedagogically-based activities to make the most of the available technologies.

\section{2 iPads as a mobile learning device for fieldwork}

Mobile learning is now taking place on a range of smart phones and tablets, the capability and functionality of which continues to rapidly expand. Here iPads are used as an exemplar of mobile technologies that essentially enable a "one stop" learning device for use in the field. At the time of the inception of this research a number of devices were investigated and the iPad was selected because of its broad functionality and durability (with appropriate protection) for field work. It is worth noting that all of the benefits discussed in this paper and those outlined by Melhuish and Falloon (2010) are also relevant to many other tablets in the modern tablet market and are not limited to the Apple iPad.

The Apple iPad 2 tablet was released in 2011 with the most notable upgrades from the original iPad being the increased processing power, its lighter weight and the addition of front and rear cameras. It is not the intention of this paper to focus on the technical capabilities of the iPad 2; the focus lies on the pedagogic benefits it can provide, how students perceive iPads as suitable devices to facilitate mobile learning within fieldwork and how mobile learning may impact on the student experience of the field course. Melhuish and Falloon (2010) identify that "The [original] iPad's size and weight potentially makes it ideal as a portable learning device"(p.5) and note that the portability should make the "iPad ideal for use in fieldwork"(p.6) . Furthermore, Johnson, Adams \& Cummins (2010) suggest that the iPad will be suitable for "recording real-time observations or accessing references on the fly". Melhuish and Falloon (2010) state that though the iPad may have many similar traits to smartphones and laptops, it negates the need to have a mouse, does not have a small screen like smartphones, is not as cumbersome as a laptop and offers a usable keyboard whilst also being a powerful, portable computer.

As the iPad increases in popularity, innovative uses for fieldwork across a range of disciplines have been explored. 
- Bunting and Fearnley (2011) made use of iPads for field mapping using remotely sensed images and also made use of Twitter and Flipboard to enable students to access and share information during fieldwork.

- Wilson (2011) used an iPad for geological fieldwork and described it as "the best field library I have ever had" as he used the iPad to sync resources using Dropbox, to read PDFs, to make field notes in Evernote and to make field sketches in Bamboo Paper.

- Ellis and Wallrodt (2010) outlined how the University of Cincinatti have used iPads for recording data and conducting analysis in the field during archaeological excavations of Pompeii.

- France et al. (2013) describe iPad use in bioscience fieldwork to record geotagged data and the use of Twitter to encourage student engagement on taught field days.

- Earth science students at secondary schools have demonstrated increased productivity when using iPads during classroom and fieldwork studies (Wallace and Witus, 2013)

- Medical students have been given iPads as part of their research methods course (conducted in the field) at Duke University (Winograd, 2010) to "to collect and analyze data while in the field, where it's most meaningful" (no page).

This paper describes the largest collation of data to date on students' perceptions of using iPads as mobile learning devices for fieldwork.

\subsection{Aims and objectives}

The overall aim of this research was to investigate student perceptions of using iPads during fieldwork. The objectives were:

- To identify the level of exposure the student had to mobile technologies prior to fieldtrip

- To establish how the students used the iPads during the fieldwork

- To explore student perspective about potential benefits, drawbacks and concerns of using iPads during fieldwork

\section{Method}

\subsection{Introduction}


A mixed-methodology approach was taken to this research utilising questionnaires and focus groups to gather data. A total of six fieldtrips were targeted, five from the University of Chester (geography) and one from the University of Reading (biology). There was a mixture of UKbased fieldtrips (Devon) and international fieldtrips (Spain, Naples, Iceland, New York) and data were gathered between 2012 and 2013 (Table 1). A total of 173 students across levels 4, 5 and 6 (first, second and third year of undergraduate programme respectively) responded to the optional questionnaire of which $46 \%$ were female, $53 \%$ male (1\% no data) and $91 \%$ were aged between 18-21. In addition 14 focus groups were undertaken following the field trips to Spain, Naples, Iceland and Devon (2013). Student responses were recorded and reported anonymously so that the students were free to express their views. During each fieldtrip, the students made use of six department-owned Apple iPad 2 devices which were encased in Griffin GB02480 Survivor Military Duty Cases which are able to withstand heavy rainfall, strong winds, dust and being dropped.. It is worth noting that whilst the iPad 2 weighs approximately $613 \mathrm{~g}$ (Everyipad.com, 2013), the protective case adds an additional $227 \mathrm{~g}$ to the overall weight rendering the total weight of the iPad 2 and case at $840 \mathrm{~g}$.

\section{Table 1 - Overview and number of questionnaire responses from each field trip.}

\section{2 iPad set up}

The six iPad 2s (hereafter referred to as iPads), were set up identically and each given a number between 1 and 6 . To ensure the students knew which iPad they had used, the screensaver and home screen were set up to display an image which had "iPad number 1" (etc.) on the front. This enabled students to find the iPad they had used during previous days more easily. The groups were not able to keep their iPad as there were multiple activities with multiple groups taking place across the field days. All of the iPads had a range of apps pre-loaded and included apps such as iTalk, Twitter, Numbers, Pages, Skitch, Fotobabble, PollDaddy, Panoramio, Geomeasure, GPS Log, GeoSpike, Keynote and Splice (see Table 2 for a description of the apps used and their pedagogic value).

Whenever possible, apps were used that had a data export or sharing function in order to extract the data for use post-fieldtrip. Also, most apps were used in off-line mode so that the field data could be collected regardless of access to a $3 \mathrm{G}$ connection. Each iPad also had a unique Gmail e-mail address so that students could send data between iPads or to their personal e-mail addresses. Each iPad also had a unique Twitter account and Dropbox account linked to it so that students could save and share their data in online cloud storage. Students experienced using 
some apps where data was easily exported and learned the skills to extract data from other apps where the data was more difficult to export.

Each of the six field trips had different learning objectives and aims which is why a range of apps were used. Students were able to ask if they could add apps to the iPads if they felt that they would be useful for their research but only staff members had the passwords to enable purchasing or downloading of apps to prevent students from downloading apps for personal use or apps which were unsuitable. The field courses were a mixture of taught days and project days, the latter where the students designed their own research projects and collected their own data. The students may have been influenced to use certain apps as a function of them being demonstrated in teaching activities during the first days of the field course and students may also have been influenced by which apps they used due to the nature of the research. In some instances they were asked to use the iPads for a specific purpose e.g. to make a 2 minute reflective video of their experiences or tweet concise observations of a field site using Twitter (see Table 1 for activities undertaken). While some activities were mandatory, none of them were assessed in a summative context.

\subsection{Research methods}

\subsection{Questionnaires}

Post fieldwork questionnaires were devised to gather both quantitative data and qualitative data using a range of question types including closed multiple choice and 'Likert' scale questions for a "quick-look" (Bird, 2009) and open-ended questions which gave the opportunity for participants to share their experiences with depth and richness (McGuirk \& O’Neill, 2005). The questionnaire (Q) was cleared by the University of Chester Learning and Teaching Institute Research Ethics Committee before it was made publically available. A participant information sheet was also available for all participants of the survey and participants were able to withdraw at any time. A total of 173 responses were gathered across the six field courses. Qualitative responses were analysed using thematic analysis (Guest, MacQueen \& Namey, 2011) which included the following stages: familiarisation of data, generation of initial codes, searching for themes amongst codes, reviewing themes then defining and naming themes (Braun and Clarke, 2006);

\subsubsection{Focus Groups}


In addition to questionnaires, fourteen focus groups were conducted across the six field courses. Focus groups (FG) were a complementary methodology designed to enable participants to give more detailed qualitative responses than they might usually give in written questionnaires (Kneale, 2001). Three pre-created questions were used for each focus group to initiate discussion, though the conversation flowed around these topics and additional questions were asked. The data yielded from the focus groups was rich in depth and detail. Focus groups were generally conducted by either one or two facilitators either towards the end of the field course or back at the institution shortly after the end of the field course. The focus groups lasted in the region of 10-30 minutes. On average the group size was 6 with a range of 3-10. Focus groups were recorded using an audio recording device and highlights and specific quotes were drawn from the recordings.

\section{Results}

\subsection{Students' previous experience of mobile device usage}

The students were asked about how familiar they were with the use of mobile devices, including smartphones and tablet computers (Figure 1). These data provide a baseline of the amount of experience the students had with these technologies prior to using them for fieldwork learning.

\section{Figure 1 - Percentage of student familiarity with mobile devices.}

The data (Figure 1) show that in 2012/2013 iPhones, smartphones and iPod touch devices were more commonly owned by students than iPads or tablet devices, indeed, the results show that $84 \%$ of the students surveyed own either an iPhone or other smartphone device. However, iPads and tablets are less commonly owned with only $6 \%$ owning a different tablet and $16 \%$ owning an iPad. Despite the lower ownership of tablets in general, iPads specifically were found to be infrequently used by $57 \%$ of the students and only $12 \%$ of the students had not used the device at all prior to the field course.

\subsection{Pedagogic usage of iPads in fieldwork}

The students were asked to report the type of learning activities that they had been doing on fieldwork using the iPads. These tasks were mainly suggested by the staff but in all instances 
the students had access to the iPads throughout the fieldtrip and could use them to support their learning in whichever way they chose (see Tables $1 \& 2$ for further information).

\section{Figure 2 - Percentage of students using the iPad for a range of purposes.}

The data (Figure 2) show that the most popular use for the iPad was to use it to take photographs (83\%) followed by mapping/geotagging $(71 \%)$ and then browsing the web for information $(62 \%)$. Interestingly, out of all of the uses for the iPad, only $31 \%$ of students used it for word processing. The students found that having multiple options on one device allowed them to use different apps which yielded unexpected results, "I am very much a physical learner, so I find writing things is the best way for me taking notes, but I found the Splice video was there for reflection. Looking at my notes, I would not have the same level of reflection" (Spain FG, 2012). Students also commented how they used multiple apps to analyse the data and prepare it for the on-site presentations required as part of the field course assessment "We used Keynote and Numbers. I did the graph in Numbers (see Table 2) and uploaded it into Keynote." (Devon FG1, 2013). Other students commented on how they were engaged with their learning using the iPads and the apps and shortened their data collection (see Table 1) "We used geotagging, which was geospike." "That made it really fun on the Totnes day." "That made it really easy that day" "Yeah, it did, it simplified it so much" (Devon, FG6, 2013).

\subsection{Benefits of iPads}

The quantitative data presented are from the questionnaires alone. The data are reported here as a percentage of students that responded to each question. In general, all 173 students gave answers to all of the questions on the questionnaire. The qualitative data reported here are results from both the questionnaires $(\mathrm{Q})$ and the focus groups (FG) as indicated in parentheses

\subsubsection{Convenience}

Across the questionnaires and focus groups, students cited a wide range of benefits they found in relation to using the iPads. Convenience was a major benefit when considering the iPads as 
a fieldwork tool and $26 \%$ of the responses described the iPads as "quick" or "easy" to use (Figure 3). A range of factors contributed to these descriptions including the speed at which the iPads could be turned on and off, the speed at which they could change between apps and the quick access to a range of resources either on Dropbox or via the internet. Students thought that the use of this type of technology in the field is "really useful and helps things flow quicker" (Devon, FG8, 2013) and describe it as "Probably easier to use. More accessible, less time consuming than if technology was not used" (Devon, FG5, 2013). 13\% of the student responses also found the iPads useful as they negated the need to carry multiple devices or indeed notebooks with them during the fieldwork which they considered to be a benefit. Essentially, access to the iPads reduced the amount of equipment the students needed to carry in the field, which previously included notepads, pens, maps and laptops. Students referred to them as the "all-in-one" (New York, FG, 2012) that "brings everything together" New York, FG, 2012). Furthermore, the students considered the iPad useful for keeping all of their data in one place which meant they also had the data backed up as a digital copy. The students also found that it was easier to carry and filter through resources on the iPad, preferring this format to having "wads of sheets to go through" (Naples FG, 2012). Another benefit (7\% of responses) described by the students in terms of convenience was that the iPad in their durable cases meant that they were waterproof and many students preferred this to pen and paper which would have "turned to mush" (Naples, FG, 2012) in heavy rainfall.

\subsubsection{Data recording device (photos/videos/audio/mapping)}

When considering benefits of the iPads, $19 \%$ of student responses referred to the ability to record data either using the apps, the recording devices, the camera or video recording as a main benefit of the iPads to fieldwork. This response focuses on the functions of the technology itself rather than pedagogic benefits (e.g. speed of data capture or ability to view data in the field).

\subsubsection{Engaging/interesting/fun}

Only $4 \%$ of the student responses in the questionnaires described the iPads as interesting, fun or engaging. Students "found the iPads really interesting. It's a lot more interesting than just grabbing a notepad." (Devon, FG5, 2013). However, within the focus groups, there seemed to be a greater emphasis on this aspect of using iPads perhaps because of the more informal 
environment the students were able to look back and discuss the social and enjoyable aspects of using iPads for learning (compared to their questionnaire answers that were more focussed on the learning outcomes). The general opinion from the New York focus group was that the access to the iPads, Wi-Fi hotspots and social networks, such as Twitter, allowed the students to record their thoughts more "interactively and entertainingly" (New York, FG, 2012) throughout their fieldwork.

\subsubsection{Reflective learning and communication}

Just $1 \%$ of the survey responses focused on how the iPads were useful for reflective learning and communication though again this was explored by some of the students in the focus groups. The iPad encouraged the students to reflect on what they had done that day. "It made us think about other things at the site... it helped me think and expand upon ideas and problems" (Spain, FG, 2012). However, the device made the students feel more connected with the other groups through the social media apps such as Twitter.

\subsubsection{Immediacy}

Again, just $1 \%$ of the students surveyed focused on the benefits of using the iPad in terms of immediacy, but this was also discussed in the focus groups. The students discussed how the device saved them time by starting their analysis whilst still out in the field, "We used the iPad to record data (see Table 1) for the infiltration day so it uploaded it all onto a spreadsheet. Suppose that was better because we could just make a graph straight away; it means that you are spending less time sorting data. It means that you don't have to spend time back in the lab just uploading it" (Devon, FG6, 2013).

\subsection{Limitations}

\subsubsection{Connectivity}

The students identified a number of common limitations of using the iPad 2 across all of the fieldtrips (Figure 4). 38\% outlined the lack of 3G signal in the field ("Not always a 3G service which was needed for the apps to work effectively" Devon, Q, 2012) or lack of wi-fi signal at the fieldtrip accommodation as the biggest drawback ("Wireless in hotel wasn't very good and so getting information was difficult" Naples, Q, 2012). Some students described how some apps (such as Twitter) would save their data until they were in a $3 \mathrm{G}$ or wireless location but 
other students reported that they lost data when the signal dipped while something was being saved. Some students felt that if they had had access to reliable Wi-Fi they would have used the internet to find additional resources for their research (see Table 1).

\subsubsection{Cumbersome}

$11 \%$ of students stated that they felt the iPad was heavy, cumbersome or difficult to carry when out in the field. The students rightly pointed out that "the casing makes it quite heavy and less portable" (Iceland, Q, 2013). There were also issues with the protective case making it more awkward to take photographs than usual (2\% of respondents) "the camera was hard to use due to the case on the iPad" (Naples, Q, 2012). Furthermore, 5\% of respondents described difficulty reading the screen due to glare in sunny or bright conditions.

\subsubsection{Lack of familiarity}

$8 \%$ of respondents described a lack of familiarity with either the device or the apps used as being a drawback of using the technology. Though one student described this in positive terms outlining learning from his/her peers "I had to ask others what to do at times as I was unfamiliar with using the device" (Naples, Q, 2012).

\subsubsection{Insufficient devices}

Only $3 \%$ of students stated that there were insufficient iPads for the group to use. One of the issues described was that either one person dominated the use of the iPad during group work therefore not everyone had the opportunity to use the device during the fieldwork "certain people hogged it that were used to using them" (Devon, Q, 2012). Another issue focused on the student being "unable to locate "their" iPad which had their data stored on it as it was not always organised as to which group had which iPad" (Iceland, Q, 2013).

\subsection{Concerns}

The students were asked if they had any concerns about using the iPad 2 devices during the fieldwork. A number of common themes arose across each fieldtrip, yet in many cases, the concerns were initial concerns which became unfounded once the students had used the iPads (see section 3.6 changing perceptions). Importantly, $31 \%$ of the respondents stated that they had no concerns at all. 
The overwhelming concern that arose from each fieldtrip was the students worried about damaging or losing the iPad and "felt a great sense of responsibility for it" (Naples, Q, 2012). $35 \%$ of the responses stated that damage or loss was a concern. The student responses often cited the cost of the device for example the "very expensive equipment that I didn't want to break!"(Devon, Q, 2013), the rugged terrain "Yes, mountain trekking and water sampling with an iPad. Hard to judge how safe for the iPad it is to be exposed" (Iceland, Q, 2013) or poor weather conditions "it would get damaged in the wet conditions" (Devon, Q, 2012) as factors adding to their concern. Of particular note, one student "felt concerned about getting them [the iPad 2] wet, which forces you not to get it out" (Devon, Q, 2012) However, upon reflection, some students suggested that their initial concerns of damage were unfounded as they "now realise they are quite sturdy" (Devon, Q, 2012) and believe that the "protective case makes a difference" (Iceland, Q, 2013). One student noted that he/she was "worried that they [the iPad 2] might get damaged" (Iceland, Q, 2013) but happily concluded that "they all survived!" (Iceland, Q, 2013)

Personal safety was an additional a concern for 5\% of students; mainly those working in an urban environment as they were initially concerned about theft of the item due to the cost and desirability of the iPad as "Naples is a dangerous city for theft. However, once I had used it [the iPad 2], I was no longer concerned" (Naples, Q, 2012). Students were not nervous about using the expensive equipment in New York, due to the nature of the environment they were in. In New York iPads are popular and "everyone seems to have one" (New York, FG, 2012), which made the students feel more secure about using them in public. However, back in the UK students commented that it would not be as safe to use them openly (New York, FG, 2012) though none of the students on any of the other field trips mentioned personal safety or theft as an issue.

Another concern conveyed by $4 \%$ of students was the unfamiliarity with the device and $8 \%$ stated that they were unfamiliar with the software and expressed being "afraid of the unknown" (Devon, Q, 2013).

\subsection{Changing perceptions}

Students were asked whether they felt their perceptions of the use of iPads to support their learning had changed over the course of the fieldwork. $72 \%$ of the students stated that their 
perceptions of the device had improved over the course of the fieldwork. Only $3 \%$ of participants felt that their perceptions of the iPad had changed negatively by the end of the fieldwork. $14 \%$ felt that their perceptions had not changed and $11 \%$ did not answer the question.

Almost three quarters of the student participants describe their perceptions changing positively for a range of reasons. Some participants described their perceptions of the device itself changing "My perception has greatly changed, prior to the trip I saw it as a silly version of ipod/laptop but I realised how useful it was" (Devon, Q, 2012). Other participants describe how their perceptions have changed in terms of learning in a fieldwork context "it was easier to capture things in the field and bring them back for reflection instead of forgetting notes, things said/missed" (Devon, Q, 2012) and identified the usefulness of the information held by the device "Became easier to use over the course of the trip, it was useful to have data out in the field" (Devon, Q, 2013). A small number of students recognised the value that the iPad has in terms of engagement and stated that iPads "can make non interesting tasks more fun and keep you interested more" (Devon, Q, 2013). Some students described a complete change in their perceptions of using the device over the course of the fieldwork "From feeling sceptical to feeling dependent on its use" (Iceland, Q, 2013).

Despite $14 \%$ of respondents stating that they did not feel their perceptions had changed, this was not always described negatively. In some instances, students owned an iPad and were aware of their capabilities "Nothing changed, I knew they would be useful" (Devon, Q, 2013) or had high expectations of the iPad which did not diminish over the course of the fieldwork "Thought it would be helpful before. Found it very helpful after" (Devon, Q, 2012). Though in some cases student perceptions did not change but were described negatively "My perceptions did not change at all, only that it is more complicated than first thought" (Devon, $\mathrm{Q}, 2012)$.

Some students focused on the perception of the device with regards to safety and the fieldwork environment. Focus group participants from the Spanish field class (see Table 1) found the use of iPads daunting at the start of the fieldwork and did not think this technology would be appropriate for use in the physical environment. Students were concerned that they would drop the equipment, but by the end of the fieldwork, were reassured by the protection of the cases. This was further supported by participants of the Devon field course whose perceptions focused on functionality of the device in different weather conditions "I now know they work in all 
weathers and are easy to use" (Devon, Q, 2012) and found them to be "more durable than anticipated" (Devon, Q, 2012).

\section{Discussion}

\subsection{Student exposure to technology}

The results presented here show that these students had a high level of exposure to digital technologies prior to the field courses and many skills acquired using smartphones are transferable to tablet computing. $84 \%$ of the students either owned an iPhone or other smartphone device at the time of completing a survey, this figure confirms the projected shift from standard mobile phones to smartphone ownership as predicted by data analysed by Welsh \& France (2012). Only $22 \%$ of the students owned either an iPad or tablet device (data collected 2012-2013), though it is likely this number will grow over the next few years in line with current tablet growth figures and evidence from other more recent studies. For example, Gartner (2014) stated that "In 2013, tablets became a mainstream phenomenon" and outlined that tablet sales had increased by $68 \%$ by 2013 compared to 2012 (Gartner, 2014). Howe et al. (2014) similarly found that smartphone and tablet ownership "has risen steadily over the years" with $93 \%$ of students at the University of Northampton owning smartphones and 54\% owning tablets. Despite not owning their own tablet device, $57 \%$ of the students in this research specified that they had used the iPad infrequently and a further $27 \%$ have used another tablet infrequently and just $12 \%$ of the students stated that they had never used an iPad before they embarked on the field courses. These figures highlight how embedded digital technologies are within the lives of students. Bunting \& Fearnley (2011) reiterate this and found that "ease of use with no previous iOS experience" was the main benefit to using iPads (specifically an Apple device rather than any other tablet) during fieldwork as it reduced the amount of time needed to teach students how to use the technology and enabled the students to get on with collecting and analysing data. Fletcher et al. (2007) found that staff frequently did not want to use technology during field courses as they felt the technology was too complex and the students took a long time to learn how to use the technology. However, with technology becoming more intuitive to use and ubiquitous in the everyday life of a modern student, practitioners should embrace the technological knowledge that students already have and use this to enable the students to apply the technology for pedagogical purposes. 
Welsh et al. (2013) found that $20 \%$ of fieldwork practitioners thought that in general practitioner incompetence and unwillingness was a barrier to adoption of technology and O'Bannon \& Thomas (2014) found that in some cases the age of the practitioner had an effect on whether mobile technologies were used in the classroom. Welsh et al. (2013) suggested that "perhaps the current generation of simple, intuitive app-driven software available for use on tablets and smartphones will alter practitioner's perceptions of technology being complicated or time consuming". The data presented within this paper should eliminate many of the concerns practitioners have about their own or their colleagues' lack of competence with app driven technologies and the findings presented here should certainly demonstrate that the vast majority of students have the capabilities and level of knowledge to use these app-driven technologies in the field effectively with the right amount of guidance from tutors about which apps might be suitable for certain activities. Only $4 \%$ of the students surveyed within this research voiced concerns over unfamiliarity of the device and $8 \%$ had concerns about unfamiliarity with the software yet even this small number of concerns could be eliminated with a short familiarisation session in lectures or teaching sessions enabling students to become more comfortable with the devices at the University prior to the field courses.

\subsection{Student usage of the iPad}

The students surveyed indicated that they used the iPad in a range of ways, most popularly for taking photographs, mapping or geo-tagging, browsing the web and editing videos or photographs. Other uses included recording audio or video and recording, analysing and preparing data for presentation. When describing the benefits of the iPads, the students largely focused on the technology aspect of the device with $26 \%$ recognising the device was convenient as an all-in-one or multi-tool device which negates the need to carry multiple devices. Furthermore, $19 \%$ of responses focused on the device's ability to record data through photographs, video or audio. Only $4 \%$ of the survey responses described the iPads as fun, engaging or interesting, only $1 \%$ recognised their relevance as a reflective tool and less than $1 \%$ recognised that the benefits that the immediacy the device can bring. These findings do not fully align with practitioners perspectives of why they introduce technology into field courses. Welsh et al. (2013) found that $63 \%(n=73)$ of practitioners indicate that data processing such as data collection and analysis was the main reason for introducing technology 
into a field course followed by student skills development which $49 \%(\mathrm{n}=73)$ of practitioners cited as a key reason to incorporate some form of technology into field courses.

Both the students and practitioners identified that technology can be used to speed up/improve data collection; but there was not much further overlap in their thinking. When specifically questioning students about the benefits of using the iPads they tended to focus on the technological aspects rather than the pedagogic benefits, yet when asked about how their perceptions of the device had changed, only $3 \%$ described their perceptions of the device as changing negatively and over three quarters stated that their perceptions of the device as a learning tool had changed positively with many recognising how useful the device was. However, the data presented show that the students do not explicitly recognise the pedagogic benefits of mobile devices for fieldwork such as increased engagement, use as a reflective tool and skill enhancement and tended to view the iPads as a piece of technology rather than a learning tool unlike the practitioners who wanted to introduce mobile technologies for their pedagogic benefits (Welsh et al., 2013).

\subsection{Connectivity in the field}

Issues arising from connectivity of the devices such as poor or non-existent $3 \mathrm{G}$ signal out in the field or Wi-Fi connections at field work accommodation were cited as an issue which prohibited the students from using the devices to their full capacity during fieldwork. In the UK 4G and even 5G (Techradar, 2014) connectivity is being discussed for implementation in urban areas yet in many rural areas (where much physical geography and geology fieldwork takes place) even basic broadband and $3 \mathrm{G}$ connections are insufficient with the Countryside Alliance stating that "life in a digital age does not yet extend to the countryside" (Countryside Alliance, 2014a). Reduced connectivity in rural areas was an issue also faced by Williams, Wong, Webb \& Borbasi (2011, p.1328) who stated that "the trial in a remote setting tested the portability of the iPads and has made students aware of serious limitations of the iPads in certain extreme conditions where Internet connectivity may be intermittent which could result in loss of location based services". Even if $3 \mathrm{G}$ signal was available in some rural areas, the physical landscape can also impede the $3 \mathrm{G}$ signal as valleys, cliffs and mountains can block the close to line-of-sight transmission required. Ultimately, connectivity is one of the major barriers when trying to use technology in rural locations, yet even in some urban locations such as New York City, students found that $3 \mathrm{G}$ connectivity regularly dropped and they had to find 
free Wi-Fi spots within the city so that they could stay connected, a luxury not extended to those conducting rural fieldwork. The poor connectivity issue has also been highlighted as an issue for other disciplines such as student paramedics who were "reliant on good Internet connectivity for location based services" (Williams et al., 2011, p.1328) when using mobile technologies in their fieldwork.

This research found that the students wanted to use the iPads to browse the web and found it useful having access to the web when out in the field, yet without reliable $3 \mathrm{G}$ or $\mathrm{Wi}-\mathrm{Fi}$, this is not possible and is a key issue which must be addressed at a national level. The current aims of the UK government are to ensure that $95 \%$ of rural communities have $4 \mathrm{G}$ access by 2017 (Countryside Alliance, 2014b) which would undoubtedly improve the ability of mobile devices to connect wirelessly to the internet in the field. However, this aim is limited to the UK alone, therefore connectivity is likely to be one of the major barriers to using mobile devices for rural fieldwork for the next 5 years both in the UK and abroad. Fieldtrip leaders who wish to use mobile technologies during field work should also be aware of the need for a good wireless (Wi-fi) signal when selecting accommodation for fieldwork.

Although poor $3 \mathrm{G}$ signal can be considered a problem when using some apps on an iPad, many app developers, (e.g. EDINA, Fieldtrip-GB) are becoming more aware of the need for 'offline' apps to use on mobile devices so that users do not have to succumb to $3 \mathrm{G}$ data charges in the UK or abroad. Using the device for taking photographs is not limited to whether there is connectivity or not, the main limitations found within this research lie in some of the mapbased apps which rely on spatial data. Students should not lose the immediacy of obtaining answers in the field or in the fieldwork accommodation just because connectivity is an issue and this will be a challenge for fieldworkers and app developers in the coming years.

\subsection{Institution-owned devices and Personal Learning Environments}

Literature suggests that institution-owned devices may not enable to students to access all capabilities of the technology as they do not have the time and permission to fully personalise the device. However, only $3 \%$ of the students surveyed commented that the lack of an individual device proved to be an issue for some reason e.g. not enough time with the device due to large group sizes, individuals monopolising the device for their personal use or difficulties in sharing data on group shared iPads. It is perhaps surprising that so few students 
mentioned issues sharing the six iPads given that some of the field courses had over 60 participants and raises the point that perhaps increasing the number of devices available may not be necessary for the students to gain the maximum benefit, but that changing the way in which the devices are shared and organised may be necessary. For example, thought needs to be given to data sharing and export from the device or the use of apps that allow cloud or online data storage once the device has been passed on or returned.

Whilst iPads have many benefits when used during fieldwork, iPads are viewed by some as personal learning environments (Whalley et al. 2014) and they could be significantly more effective during fieldwork if the device was student owned and could be personalised to suit the student's own learning. Practitioners often cite that there are insufficient funds available to purchase a device for each student, but in the case of fieldwork, even if there was a device per student, the student would have to spend considerable time personalising their device for just a short fieldtrip as the iPad is essentially an institutionally-owned device loaned to the student for a short period of time (i.e during fieldwork). Ideally, in order to get the most from the device for classroom or field based study, student should be given a device for the duration of their degree (e.g. Manchester Medical School (2011), University of Greenwich (2013)). If this is not possible, practitioners could look to an alternative such as Bring Your Own Device (BYOD) which is becoming a more popular idea within Universities. Despite a number of studies (e.g. Margaryan, Littlejohn \& Vojt, 2013) outlining potential inequalities between students who do and do not own mobile devices, other studies such as Kobus et al. (2013) and Duke CIT (2014) found that $96 \%$ of students on campus owned a mobile device, indeed the research presented in this study identified that $84 \%$ of students owned a smartphone. The idea of BYOD has increased in popularity in recent years, Duke Centre for Instructional Technology originally had an iPad loaner programme whereby faculties could loan a set of iPads for use in the classroom. However, this programme has now been retired in 2014 as during the 2013-2014 intake they found that " $96 \%$ of incoming Duke freshmen reported that they owned a web-enabled handheld device" (Duke CIT, 2014) and therefore the new focus of the institution in terms of mobile learning will now will be on implementing BYOD and this may also be a future focus for practitioners who want to introduce technology to their field courses.

\subsection{Portability of mobile devices.}


One of the main benefits identified by $13 \%$ of the students when considering the iPad was the all-in-one capabilities, effectively negating the need for multiple pieces of technology due to the device being able to collect a wide range of media and perform a range of tasks (Table 2). Many of the students liked that they could be used in adverse weather with the protective cases when pen and paper would not have been suitable. Classroom-based studies (e.g. Kobus et al. 2013) have found that students often leave their laptop or tablet at home as they find them to be cumbersome and $11 \%$ of students in this study felt that this was an issue with the iPads. At the time of beginning the research into mobile devices and fieldwork, all tablet computers with capabilities suitable for fieldwork had $~ 9.7$ " screens and most smartphone screens were under $\sim 5$ ". Many view traditional smartphone screens as too small for data entry or for browsing the web or viewing maps. Yet whilst a 9.7" tablet is much more suited to a range of fieldwork activities, it is likely that the middle sized tablets ( 7" such as the iPad mini or Kindle Fire HD) may be more suited to fieldwork activities and perhaps not feel as cumbersome to students as the larger tablets.

\section{Conclusions}

Ownership of mobile technologies will continue to grow and will become even more engrained in the lives of students. The research presented here has demonstrated that students are increasingly comfortable with using technology for academic purposes and tend to need significantly less "set-up" time teaching them how to use the technology and enabling more time to conduct research, particularly during field courses. The findings described within this research support the findings of Welsh et al. (2013) and concur that app-driven software on tablet devices is a quick and easy way to use technology to support learning on a field course. However, whilst students may be comfortable with using technology for academic purposes, this is largely due to the direction of the practitioner who, in all of the field trips outlined here, has guided them in some way with which apps might be most appropriate for their research. A recent study of undergraduate students Woodcock et al. (2012) found that many who own smartphones were largely unaware of their potential for their own education which suggests students still rely on the guidance of their instructors. Whilst there was a clear set of pedagogic justifications from practitioners about why they introduced technology into their fieldwork teaching methods; this did not translate to the students' understanding of why they were using it. There needs to be an initiative that finds ways to bridge this gap in understanding so that the 
students are made aware of the skills they are developing on fieldwork (and during their studies in general). It is often cited (e.g Wainwright 2012, Kinash, Brand \& Mathew, 2012; Karsenti $\&$ Fievez, 2013) that technology can engage students and improve motivation, yet few of the students within this research recognised that; perhaps suggesting that technology has become so normal to them, it is no longer as exciting in terms of engagement as it perhaps it once was.

In more practical terms, connectivity is likely to be one of the major barriers to using mobile devices for both urban and rural fieldwork for the next few years both in the UK and abroad. Rural fieldwork locations in particular are at risk of not having sufficient connection for students to use the mobile devices to their full potential. A potential way of circumventing this is for app developers to make their apps operate "offline" where possible, yet still this does not address the lack of access to the internet which makes mobile devices so useful when out in the field and there is a real danger than the mobile device would lose its "do-it-now-ability" (Mercer, 2010) and lose the immediacy of knowledge that mobile devices have the potential to bring to the student in the field. As outlined at the start of this paper, the iPad is just one of many mobile devices that could be used for fieldwork, yet as technology evolves, the use of the iPad mini, Kindle Fire HD or similar 7-inch screens may become more prevalent and may indeed be the optimum screen size which suits the need of the field worker who is selecting a mobile device rather than the smaller smartphone or larger tablet. Additionally, some of the newest smartphones (e.g. iPhone 6) have a larger (5.5") screen than more traditional smartphone screens and thus, it is better to focus on the optimum screen size for using during fieldwork rather than specific device (e.g.tablet or smartphone).

A final point of note is the urgent need to explore BYOD as a possibility for fieldwork. The BYOD approach (supported with a small class set of mobile devices to solve any inequality issues for those who do not have their own devices) could provide students with the opportunity to personalise their own technology-enhanced learning during fieldwork (Whalley et al., 2014).

\section{Reference List}

Bird, D.K. (2009). The use of questionnaires for acquiring information on public 
perception of natural hazards and risk mitigation - a review of current knowledge and practice. Natural Hazard Earth System Science, 9, 1307-1325.

Braun, V. \& Clarke, V. (2006) Using thematic analysis in psychology. Qualitative research in Psychology, 3 (2) p. 77-101.

Bunting, P. \& Fearnley, C. (2011) Using iPads and applications for geography fieldwork. Retrieved from: http://nexus.aber.ac.uk/xwiki/bin/download/Main/Enhancing+fieldwork+learning/Enhancing FieldworkLearningShowcaseEvent.pdf Retrieved 09.03.14

Countryside Alliance (2014a) Retrieved from: http://www.countryside-alliance.org/ca/4gbroadband [Retrieved on: 20.05.14]

Countryside Alliance (2014b) 'Digital apartheid' still evident in broadband services in the countryside. Retrieved from:http://www.countryside-alliance.org/ca/4g-broadband/digitalapartheid-still-evident-in-broadband-services-in-the-countryside[ Retrieved on: 20.05.14]

Duke Centre for Instructional Technology (2014) Retrieved from: http://cit.duke.edu/ipad/ [Retrieved on: 07.03.14]

Ellis, S. \& Wallrodt, J. (2010) Using tablet PCs to support field documentation. Retrieved from: https://www.ocs.soton.ac.uk/index.php/CAA/2012/paper/view/680

Everyipad.com (2013) Technical specifications for the iPad and iPad 2. Retrieved 08.02.14 
Fletcher, S., France, D., Moore, K. \& Robinson, G., (2007). Practitioner Perspectives on the Use of Technology in Fieldwork Teaching. Journal of Geography in Higher Education, 31(2), 319-330.

France, D., Whalley, W. B., \& Mauchline, A. (2013) Using Mobile Devices to Enhance Undergraduate Field Research. CUR Quarterly. 34 (2) p. 38-42. Washington, DC: Council on Undergraduate Research.

France, D., Welsh, K.E., Powell, V., Mauchline, A., Park, J.R \& Whalley, W.B. (2015 forthcoming) Enhancing Fieldwork Learning Using Digital Technologies. Springer.

Gardiner, V. \& Unwin, D. (1986) 'Computers and the field class', Journal of Geography in Higher Education, 10, 169-79.

Gartner (2014) Gartner Says Worldwide Tablet Sales Grew $68 \%$ in 2013, With Android Capturing $62 \%$ of the Market. Retrieved from: http://www.gartner.com/newsroom/id/2674215 [Retrieved on: 28.05.14]

Gikas, J. \& Grant, M.M. (2013) Mobile computing devices in higher education: student perspectives on learning with cellphones, smartphones and social media. Internet \& Higher Education (19) 18-26.

Guest, G., MacQueen, K. M., \& Namey, E. E. (2011). Applied thematic analysis. Sage.

Howe, R., Gordon, A. \& Farmer, R. (2014) Mobile Survey. Retrieved from: https://nile.northampton.ac.uk/bbcswebdav/orgs/LearnTech/Projects/MALT/Mobile\%20surv ey\%20reports/Mobile\%20Survey\%20Report\%20Jan\%202014.pdf

Johnson, L., Adams, S., \& Cummins, M. (2010). The NMC Horizon Report: 2010 Higher Education Edition. Austin, Texas:The New Media Consortium. 
Karsenti, T. \& Fievez, A. (2013) The iPad in education: uses, benefits and challenges - A survey of 6,057 students and 302 teachers in Quebec, Canada. Montreal, QC: CRIFPE.

Kent, M., Gilbertson, D.O. \& Hunt, C.O. (1997) Fieldwork in geography teaching: a critical review. Journal of Geography in Higher Education, 21, pp.313-32.

Kinash, S., Brand, J., \& Mathew, T. (2012). Challenging mobile learning discourse through research: Student perceptions of Blackboard Mobile Learn and iPads. Australasian journal of educational technology, 28(4), 639-655. Retrieved from http://www.ascilite.org.au/ajet/ajet28/kinash.pdf

Kneale, J. (2001) Working with groups. In Lamb, M. \& Dwyer, C. (Eds.) Qualitative Methods for Geographers issues and debates. Oxford University Press, New York.

Kobus, M.B.W., Rietveld, P., van Ommeren, J.N. (2013) Ownership versus on-campus use of mobile IT devise by university students. Computers \& Education, 29-41.

Manchester Medical School (2011) MMS iPads project. Retrieved from: http://www.mms.manchester.ac.uk/cbme/tutornotes/ipadinformationbrochure.pdf [Retrieved on: 20.05.14]

Margaryan, A., Littlejohn, A. \& Vojt, G. (2011) Are digital natives a myth or reality? University student's use of digital technologies. Computers \& Education, 56(2) 429-440.

Maskall, J., and Stokes, A. (2008). Designing Effective Fieldwork for the Environmental and Natural Sciences. pp77. HEA GEES Subject Centre.

Maw, S., Mauchline, A. L. \& Park, J. R. (2011) Biological fieldwork provision in higher education. Bioscience Education, 17. 17-1.

McGuirk, P. M. and O’Neill, P.: Using Questionnaires in Qualitative Human Geography, in: Qualitative Research Methods in Human Geography, edited by: Hay, I., Oxford University Press, Australia, pp. 147-162, 2005. 
Melhuish, K. \& Falloon, G. (2010). Looking to the future: M-learning with the iPad. Computers in New Zealand Schools: Learning, Leading, Technology, 22(3).

Mercer, T. (2010) How will iPad affect MR? Retrieved from http://www.researchlive.com/how-will-ipad-affect-mr?/4002820.blog\#comments [Retrieval date:07.03.14]

O’Bannon, B.W. \& Thomas, K. (2014) Teacher's perspectives of using mobile phones in the classroom: age matters! Computers and Education, 74, 15-25.

Ruchter, M., Klar, B. \& Geiger, W. (2010) Comparing effects of mobile computers and traditional approaches in environmental education. Computers \& Education (54), 1054-1067.

Techradar (2014) UK to collaborate with Germany on 5G. Retrieved from: http://www.techradar.com/news/computing/uk-to-collaborate-with-germany-on-5g-internetof-things-1232346 [Retrieval date: 20.05.03)

Wainwright, K. (2012). Putting iPads in the hands of faculty. In Proceedings of the ACM SIGUCCS 40th annual conference on Special interest group on university and college computing services (pp. 139-144). New York, NY: ACM.

Wallace, D.J. \& Witus, A.E. (2013) Integrating iPad Technology in Earth Science K-12 Outreach Courses: Field and Classroom Applications. Journal of Geoscience Education. 61(4), 385-395.

University of Greenwich (2013) iPads excite students. Retrived from: http://www2.gre.ac.uk/about/news/articles/2013/a2428-ipads-excite-science-students [Retrieved on: 20.05.14] 
Welsh, K.E. \& France. D. (2012). Smartphones and fieldwork. Geography, 97(1), 47-51

Welsh, K.E., Mauchline, A.M, Park, J.R., Whalley, W.B., France, D. (2013) Enhancing fieldwork learning with technology: practitioner's perspectives. Journal of Geography in Higher Education 37(3).

Whalley, W.B., France, D., Park, J.R., Mauchline, A., Powell, V., Welsh, K.E., (2014) Ipad use in Fieldwork: formal and informal use to enhance pedagogic practice in a Bring Your Own Technology world. Proceedings of the First International Conference on the use of iPads in Higher Education 2014 20th, 21st, 22nd March 2014, Paphos, Cyprus, Retrieved from: http://ipadsinhe.org/wp-content/uploads/2014/04/ihe_2014_proceedings.pdf [Retrieved on: 26.06.14]

Williams, P., Wong, W., Webb, H., \& Borbasi, S. (2011). Mobile technologies in the field: iPads - rescuer or rescuee? In G. Williams, P. Statham, N. Brown, \& B. Cleland (Eds.), Changing demands, changing directions: Proceedings of ascilite 2011 (pp. 1325-1331). Retrieved from http://www.ascilite.org.au/conferences/hobart11/downloads/papers/Williamsconcise.pdf

[Retrieved on: 07/03/14]

Wilson, M. (2011) Using the iPad in geological fieldwork. Retrieved from: http://woostergeologists.scotblogs.wooster.edu/2011/07/02/using-the-ipad-in-geologicalfieldwork/ Retrieved on 09.03.14

Winograd, D. (2010). Duke University to use iPads for field research. TUAW. Retrieved from http://www.tuaw.com/2010/07/21/duke-university-to-use-ipads-for-field-research/ [Retrieved on: 07/03/14]

Woodcock, B., Middleton, A., Nortcliffe, A. (2012) Considering the Smartphone Learner: an investigation into student interest in the use of personal technology to enhance their learning. Student engagement and Experience Journal. 1(1), 1-15. 